\title{
OCCUPATIONAL DISEASES IN THE PERIOD OF SOCIOECONOMIC TRANSITION IN POLAND
}

\section{NEONILA SZESZENIA-DĄBROWSKA and URSZULA WILCZYŃSKA}

Department of Environmental Epidemiology

Nofer Institute of Occupational Medicine

Łódź, Poland

\begin{abstract}
Objectives: Current situation in the epidemiology of occupational diseases is a resultant of many contributing factors, such as occupational exposures of the working population, social and economic conditions, medical measures, legislation, and ongoing changes in the national economy. Materials and Methods: This work is based on the information compiled from reporting forms on occupational diseases gathered in the Central Register of Occupational Diseases run by the Nofer Institute of Occupational Medicine, Łódź, Poland. Results: A systematic downward trend in the number of occupational diseases has already been observed over several years. In 1998, as many as 12017 cases were recorded (117.3 per 100000 workers), while in 2005, this number was reduced to 3249 (34.8 per 100 000). In 2005, the highest incidence rates were noted for chronic voice disorders, pneumoconioses, infectious and parasitic diseases, hearing loss, and skin diseases. The observed decrease in occupational pathology is associated with continued transformations in the national economy. Changes in the nature and level of occupational exposures have influenced the profile of occupational pathologies. Medical preventive measures, such as vaccinations covering high-risk groups have contributed to the reduced incidence of occupational diseases. For example, the number of cases of occupation-related viral hepatitis was seven times lower in 2005 than in 1993. The 2005 data show that over $50 \%$ of occupational diseases were diagnosed in workers employed outside industry. Conclusions: Changes taking place on the labor market, new technologies and most of all transfer of the workforce from industry to the service and administration sectors, will certainly affect the profile of occupational and work-related pathologies. In the present-day environment, the work-related stress has become a dominant factor.
\end{abstract}

Key words:

Occupational diseases, Incidence, Epidemiology

\section{INTRODUCTION}

In Poland, the first regulation concerning inter alia occupational diseases was the law of 1919 [1]. By virtue of this law, every case of contagious or occupational disease had to be officially reported. However, the Decree on the prevention and control of occupational diseases, issued by the President of the Republic of Poland in 1927, was most noteworthy. This act not only contained instructions concerning the elimination of causes of diagnosed diseases, but it also imposed on sanitary inspectorate agencies an obligation to report on occupational diseases and to conduct environmental inquiry in each case. At that time, 49 nosologic units were recognized as occupational diseases. The later regulations of 1933 and 1937 were less progressive. One of their positive aspects was the fact that the former covered three, and the latter eleven nosologic units of occupational diseases by social insurance.

After World War II, the legislation concerning occupational diseases was amended several times (in 1954, 1956, 1968, 1974, 1983, 1989 and 2002), whereby the list of occupational diseases was extended. At first, two concurrent provisions were mandatory, the first one made it obligatory to report and register every case of occupational disease, the other granted the worker or his/her family the right to compensation in case of disability or death. Since 1974, the list of 14 occupational diseases has been mandatory. The

Received: April 12, 2006. Accepted: May 30, 2006.

Address reprint requests to Dr. U. Wilczyńska, Department of Environmental Epidemiology, Nofer Institute of Occupational Medicine, św. Teresy 8, 91-348 Łódź, Poland (e-mail: wies@imp.lodz.pl). 
current legislation on occupational diseases introduced in September 2002 [2] specifies nosologic units to be considered occupational, procedures for diagnosing, certification and notification of occupational diseases, and reference institutions responsible for each level of the process.

In Poland, directives on occupational diseases have been issued since 1927, and the number of diseases included in the attached lists ranged from 3 to 49, depending on different periods. The list of occupational diseases binding since September 2002 includes 26 groups of nosologic units: (1) Acute and chronic intoxications and their sequels; (2) Metallic fever; (3) Pneumoconioses (silicosis, coal workers' pneumoconiosis, pneumoconiosis associated with tuberculosis, welders' pneumoconiosis, asbestosis, other types of pneumoconiosis); (4) Diseases of pleura or pericardium induced by asbestos dust (diffuse thickening of pleura, diffuse plaques of pleura or pericardium, pleural exudate); (5) Chronic obstructive bronchitis, causing airflow limitation $\left(\mathrm{FEV}_{1}<50 \%\right.$ of predicted value) induced by exposure to dusts and irritant gases, if an excess of TLV was documented during the last 10 years of occupational exposure; (6) Bronchial asthma; (7) Extrinsic allergic alveolitis (acute or sub-acute form, chronic form); (8) Acute general allergic reactions; (9) Byssinosis; (10) Berylliosis; (11) Lung diseases induced by hard metal dusts; (12) Allergic rhinitis; (13) Edematous laryngitis induced by allergy; (14) Nasal septum perforation induced by irritant and corrosive agents; (15) Chronic voice disorders due to excessive vocal effort lasting for at least 15 years (hard vocal nodules, secondary hypertrophic changes in vocal folds, paresis of adductor and tensor vocal fold muscles with glottis insufficiency and persistent hoarseness); (16) Ionizing radiation-induced diseases (acute radiation sickness as a consequence of the whole body, or its larger part irradiation, acute radiation sickness with inflammatory or inflammatory-necrotic changes of skin or subcutaneous tissue, chronic dermatitis due to radiation, chronic lesion of bone marrow, cataract due to radiation, malignant neoplasms for which the probability of induction by radiation is higher than 10\%); (17) Malignant neoplasms induced by human carcinogens present in the work environment (lung cancer, pleural or peritoneal mesothelioma, neoplasms of hematopoietic system, skin cancer, bladder cancer, liver angiosarcoma, other neoplasms); (18) Skin diseases (allergic contact dermatitis, irritant contact dermatitis, oil acne, chloroacne, coal tar acne of the diffuse nature, candida infections, hand intertrigo, nail dystrophy with paronychia due to working conditions, dermatophyte infections due to contact with animal biological material, contact urticaria, melanodermitis toxica, contact lichen planus caused by photochemicals, occupational photodermatoses, changes in skin color due to occupational exposure to chemicals or incrustation of skin with foreign body particles); (19) Chronic diseases of the locomotor system related to the way the job is performed (tendovaginitis, bursitis, lesion of meniscus, lesion of articular capsule, periarticular inflammation of shoulder joint, epicondylitis of shoulder bone, fatigue-induced bone fracture, wrist bone necrosis); (20) Chronic diseases of peripheral nervous system related to the way the job is performed (carpal tunnel syndrome, groove of ulnar nerve syndrome); (21) Bilateral permanent noise-induced hearing loss of cochlear type, amounting to at least $45 \mathrm{~dB}$ in the healthier ear as a pure tone average for 1,2 and $3 \mathrm{kHz}$ audiometric frequencies; (22) Vibration syndrome (vibratory angioneuropathy, osteoarticular form, mixed form of angioneuropathy and osteoarticular disorders); (23) Diseases induced by work under the increased atmospheric pressure (decompression sickness, barotrauma, sequels of compressed air breathing); (24) Diseases induced by high or low temperature of the environment (heat stroke and its sequels, heat exhaustion and its sequels, frostbites); (25) Diseases of visual system induced by physical, chemical or biological agents (allergic conjunctivitis, acute conjunctivitis induced by ultraviolet radiation, epidemic viral conjunctivitis or keratitis, keratopathy, cataract, central retinal and choroidal degeneration); (26) Infectious and parasitic diseases and their sequels (viral hepatitis, borreliosis, tuberculosis, brucellosis, amebiasis, malaria, other infectious or parasitic diseases).

\section{MATERIALS AND METHODS}

In 1975, the Nofer Institute of Occupational Medicine in Łódź developed a uniform database for reporting cases of occupational disease and collecting, processing and 
retrieval of related statistics. An official form for medical certification of an occupational disease has become mandatory all over Poland. These have resulted in the uniform registration system developed in our country. The occupational disease database provided grounds for establishing the Central Register of Occupational Diseases that has been in operation since 1999.

All medically certified occupational diseases are recorded and the Central Register of Occupational Diseases is notified by the local sanitary inspector about each case. The system made it possible to compile data on all cases of occupational diseases diagnosed in Poland after 1970. Each file contains the following information: date of medical certification, country district, patient's name, date of birth, home address, name of enterprise with its code number and address, code of employer's economic activity according to NACE, workpost description, occupational agent responsible for the disease, exposure duration, disease category, name of the health service unit that diagnosed the disease.

The present report is based on the information compiled from reporting forms on occupational diseases submitted to the Central Register of Occupational Diseases.

\section{RESULTS}

In Poland, the number of occupational diseases diagnosed in 2005 amounted to 3249 cases [3]. The incidence rate was 34.8 cases per 100000 paid employees. The highest incidence rates were noted for chronic voice disorders (7.3), pneumoconioses (7.2), infectious and parasitic diseases (6.6), permanent bilateral hearing loss (3.6), and skin diseases (1.7). These diseases constitute as many as $76.0 \%$ of the total number of occupational pathologies (Fig. 1).

An analysis of the incidence of occupational diseases in the male and female working populations reveals considerable differences associated with specific working conditions in either group. Among 2021 cases (40.9 per 100000 employees) of occupational diseases diagnosed in male workers, the most prevalent were pneumoconioses, hearing loss, infectious and parasitic diseases, malignant neoplasms, chronic voice disorders, and vibration syndrome
(Table 1). Among 1228 cases (27.8 per 100000 employees) of occupational diseases diagnosed in female workers voice disorders, infectious and parasitic diseases, skin diseases and chronic diseases of peripheral nervous system were found most frequent (Table 2).

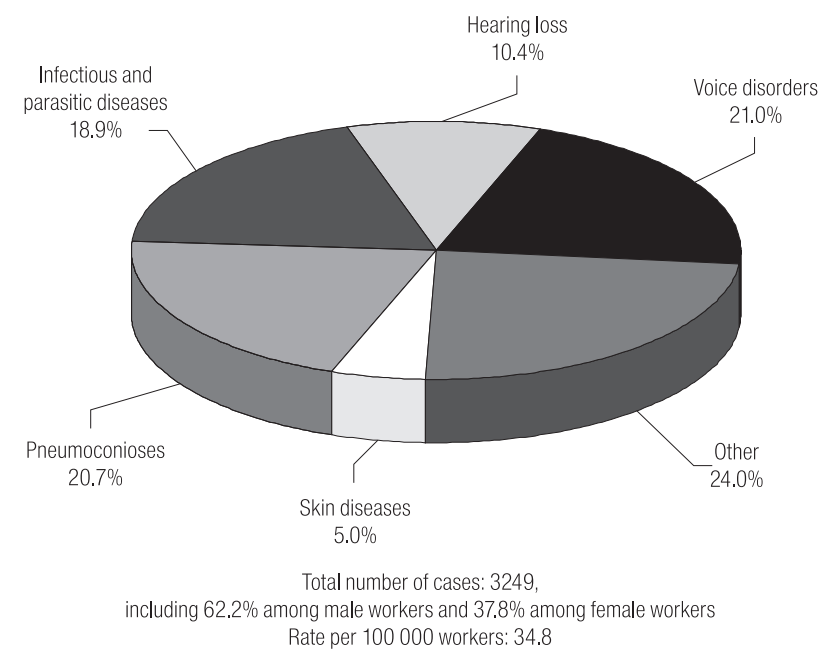

Fig. 1. Structure of occupational diseases in Poland, 2005.

Table 1. Occupational diseases with the highest incidence rate among male workers, Poland, 2005

\begin{tabular}{lcc}
\hline \multicolumn{1}{c}{ Nosologic unit } & $\begin{array}{c}\text { Incidence rate } \\
\text { per 100 000 workers }\end{array}$ & $\begin{array}{c}\text { Percent } \\
\text { of total cases }\end{array}$ \\
\hline Pneumoconiosis & 12.7 & 31.0 \\
Noise-induced hearing loss & 6.7 & 16.3 \\
Infectious and parasitic diseases & 6.5 & 16.0 \\
Chronic voice disorders & 2.3 & 5.7 \\
Vibration syndrome & 1.9 & 4.6 \\
Malignant neoplasms & 1.9 & 4.6 \\
\cline { 2 - 3 } & & Total: 78.2 \\
\hline
\end{tabular}

Table 2. Occupational diseases with the highest incidence rate among female workers, Poland, 2005

\begin{tabular}{lcc}
\hline \multicolumn{1}{c}{ Nosologic unit } & $\begin{array}{c}\text { Incidence rate } \\
\text { per 100 000 workers }\end{array}$ & $\begin{array}{c}\text { Percent } \\
\text { of total cases }\end{array}$ \\
\hline Chronic voice disorders & 12.8 & 46.0 \\
Infectious and parasitic diseases & 6.6 & 23.8 \\
Skin diseases & 1.9 & 6.9 \\
$\begin{array}{l}\text { Chronic diseases of peripheral } \\
\text { nervous system }\end{array}$ & 1.8 & 6.5 \\
& & Total: 83.2 \\
\hline
\end{tabular}


The analysis of occupational diseases revealed a low proportion $(10.6 \%)$ of young workers, under 39 years of age. The findings also indicated that in 2005, $89.2 \%$ of occupational diseases were manifested after a 10 -year period of exposure to a given hazardous agent, while $73.0 \%$ developed after a 20 -year exposure. Over $50 \%$ of occupational diseases were found in workers employed outside industry.

\section{DISCUSSION}

An analysis of the general epidemiological situation regarding the structure of occupational diseases does not indicate any dramatic changes over the last several years [4]. Since 1999, the number of diagnosed cases of occupational diseases has been steadily decreasing. In 1998, as many as 12017 cases (117.3 per 100000 workers) were recorded. In 1999, the total number of cases decreased considerably to 9982 (98.0 per 100000 workers). The respective value for 2005 was by $73 \%$ lower than for 1998. Compared to the 2004 data, a $14.3 \%$ decrease was noted in 2005 . A downward tendency is also visible in the incidence rate per 100000 workers (Fig. 2). The incidence rate of major categories of occupational diseases is shown in Fig. 3. Two groups of pathologies have mainly accounted for the decline in the number of cases recorded over the last few years: voice disorders and noise-induced hearing loss.

Over the last four decades, considerable changes have been noted in the profile and incidence of occupational diseases (Table 3). The number of cases of acute and chronic intoxications of occupational etiology, which made almost one third of all cases of occupational pa-

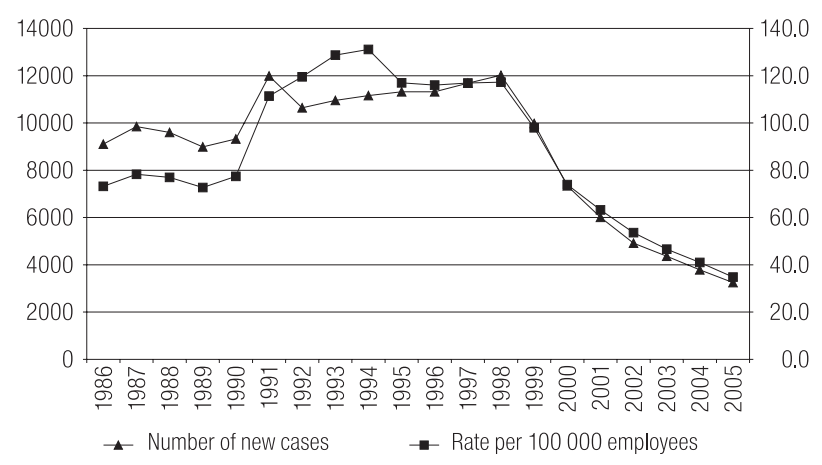

Fig. 2. Occupational diseases in Poland, 1986-2005. thologies in the late 1960s, has substantially decreased [4]. In 2005, the percentage of these events declined to $2.6 \%$. The causative factors of occupational poisonings have also changed over time. In the 1960s, exposure to lead was the most prevalent cause accounting for almost $38 \%$ of all cases of occupational intoxications. In 2005, lead poisonings made $17.4 \%$ of the registered cases while carbon disulphide intoxication was most frequent (36\%) (Fig. 4). It is worth noting that all cases of carbon disulphide poisoning recorded in 2005 were diagnosed among the former workers of the same rayon plant that stopped to operate in the past. The number of cases of acute poisonings, i.e. poisonings due to occupational exposure during an 8-hour shift, decreased by five times during the period between 1967 and 2005.

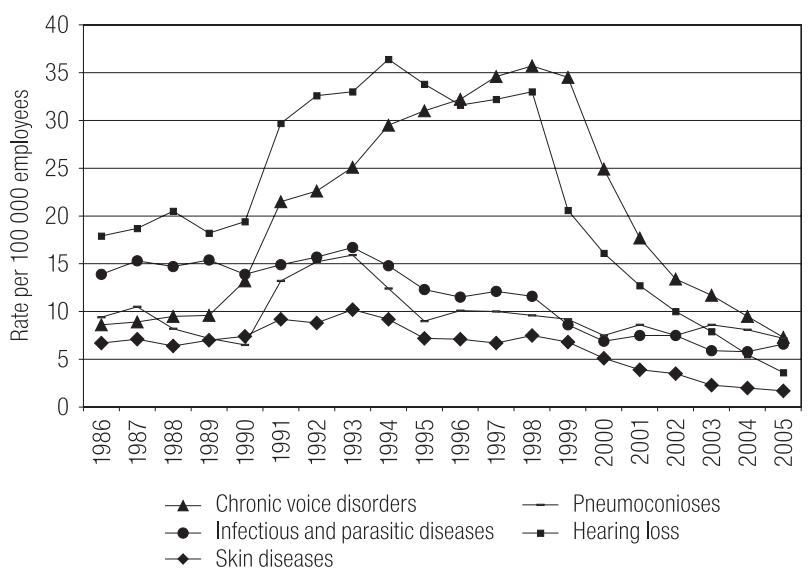

Fig. 3. Major categories of occupational diseases, Poland, 1986-2005.
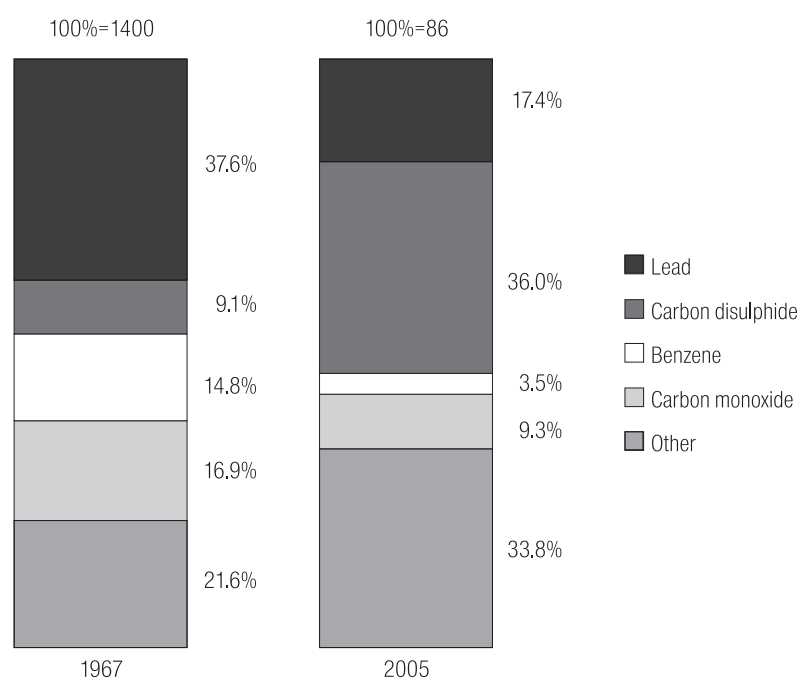

Fig. 4. Occupational intoxications in 1967 and 2005 by cause. 
Table 3. Major categories of occupational diseases diagnosed in 1967 and 2005

\begin{tabular}{|c|c|c|c|}
\hline \multirow[b]{2}{*}{ Nosologic unit } & $1967^{*}$ & \multirow[b]{2}{*}{ Nosologic unit } & $2005^{* *}$ \\
\hline & $\begin{array}{c}\text { Number of cases } \\
(\%)\end{array}$ & & $\begin{array}{c}\text { Number of cases } \\
(\%)\end{array}$ \\
\hline Chemical intoxications & $\begin{array}{l}1400 \\
(31.2)\end{array}$ & Chronic voice disorders & $\begin{array}{c}681 \\
(21.0)\end{array}$ \\
\hline Pneumoconioses & $\begin{array}{l}1130 \\
(25.2)\end{array}$ & Pneumoconioses & $\begin{array}{c}672 \\
(20.7)\end{array}$ \\
\hline Noise-induced hearing loss & $\begin{array}{c}741 \\
(16.5)\end{array}$ & Noise-induced hearing loss & $\begin{array}{c}338 \\
(10.4)\end{array}$ \\
\hline Skin diseases & $\begin{array}{c}452 \\
(10.1)\end{array}$ & Infectious and parasitic diseases & $\begin{array}{c}615 \\
(18.9)\end{array}$ \\
\hline Vibration syndrome & $\begin{array}{c}304 \\
(6.8)\end{array}$ & Skin diseases & $\begin{array}{c}163 \\
(5.0)\end{array}$ \\
\hline
\end{tabular}

* Total number of cases: 4485 ;

** Total number of cases: 3249 .

A gradual decline in the incidence of diseases that have been regarded as primary occupational pathologies, e.g., pneumoconioses and vibration syndrome, was a characteristic mark of this period. However, some of these diseases have remained as frequent as ever, for example, hearing impairments, particularly noise-induced hearing loss, which indicates that noise can still be ranked high among occupational hazards.

Along with the decrease in the rate of classical occupational diseases, starting from the early 1990s, one can note a relatively high frequency of work-related infectious and parasitic diseases. This group of diseases includes mainly cases of viral hepatitis and tuberculosis among health care workers, and borreliosis among agriculture and forestry workers. However, between 1993 and 2004, the incidence rate for these diseases was gradually decreasing. The absolute number of cases recorded among health care workers shows a downward tendency. As to viral hepatitis, the noticeable decline in its incidence seems to be the effect of prophylactic vaccinations in high-risk groups of workers. In 2005, as many as 151 cases of viral hepatitis were recorded, including 105 cases of HCV infection (Fig. 5). The 2005 data indicate a change in the trend of infectious and parasitic diseases. A 14\% increase was noted compared to the earlier period. This must have been mainly due to a considerable increase $(36 \%)$ in the number of borreliosis cases. Pneumoconioses were ranked second with regard to the number of cases in 2005 with the incidence rate of 7.2 per

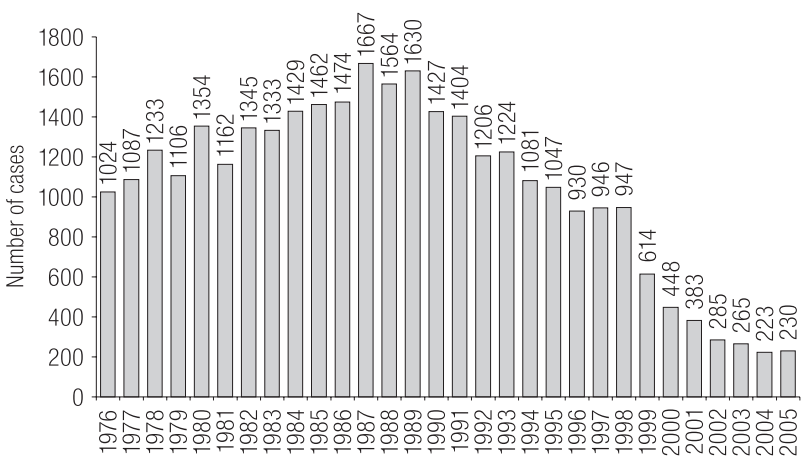

Fig. 5. Infectious and parasitic diseases in the medical staff, 1976-2005.

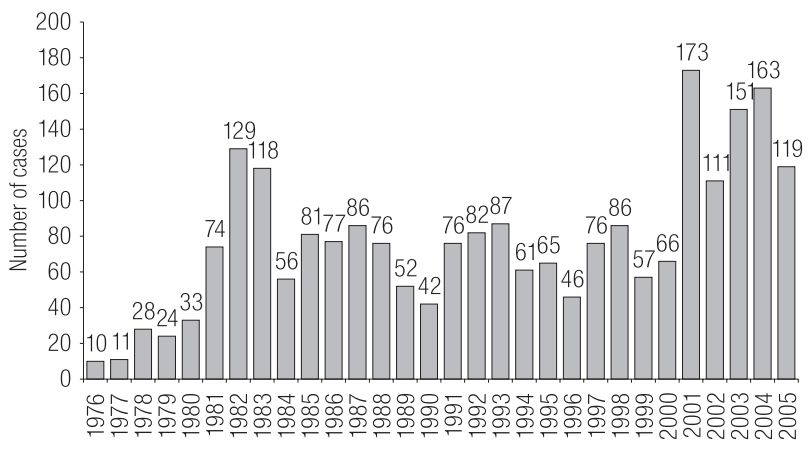

Fig. 6. Asbestosis in Poland, 1976-2005.

100000 workers. Asbestosis made almost $18 \%$ of the total cases of pneumoconiosis. In 2001, over a 2.5-fold increase in the number of asbestosis cases was recorded and, as shown in Fig. 6, this elevated level maintained also in 2002-2005. This tendency is most likely due to the prophylactic program addressed to former asbestos workers. The period between the 1970s and 1998 was characterized by an enormous outburst of voice disorders due to the ex- 
cessive vocal effort that has been recorded among persons representing educational professions. An almost 30-fold increase in the number of cases was observed, from mere 37 cases in 1975 to 3654 in 1998. Recently, a slightly declining tendency has been observed with the number of cases falling down to 681 in 2005 . This pathology mainly applies to female employees (teachers, nursery school workers and other teaching staff). Paresis of adductor and tensor vocal fold muscles with glottis insufficiency and persistent hoarseness was most prevalent making $63.3 \%$ of the total number of cases recorded in 2005.

Medical as well as social factors may have contributed to the gradual decrease in the number of voice disorders. Over the period of 1990-1998, a large number of teachers with a long work history were either dismissed from work or granted disability pension due to the certified occupational disease. It should be stressed that this downward tendency was preceded by a several-year period of a dynamic increase in the incidence of these diseases making them the major group (35.7\%) of occupational diseases in Poland in 1998. On the other hand, many teachers were afraid of being dismissed in the case of their application for disability pension due to occupational disease, especially in the period of the education system reform, and they may have not reported their cases. At the same time, more advanced diagnostic equipment has become available at many health centers, which made the diagnosis of voice disorders more objective. Also a nation-wide health education program on voice disorders in teachers started to be implemented. Under this program, knowledge of and training in voice emission have been promoted via professional publications and training courses addressed to physicians and specialists in logopedic voice therapy. This activity is regarded as the main instrument that can help reduce the number of voice disorders in teachers $[5,6]$. In 1992, the "classical" types of occupational diseases (poisonings, pneumoconioses, hearing loss and vibration syndrome) made almost a half of the registered cases while the "non-classical" ones, including voice disorders, infectious and parasitic diseases and skin diseases, constituted less than 40\% (Fig. 7). In 1996-1997, the proportion of these two categories was almost equal (about 45\%), while

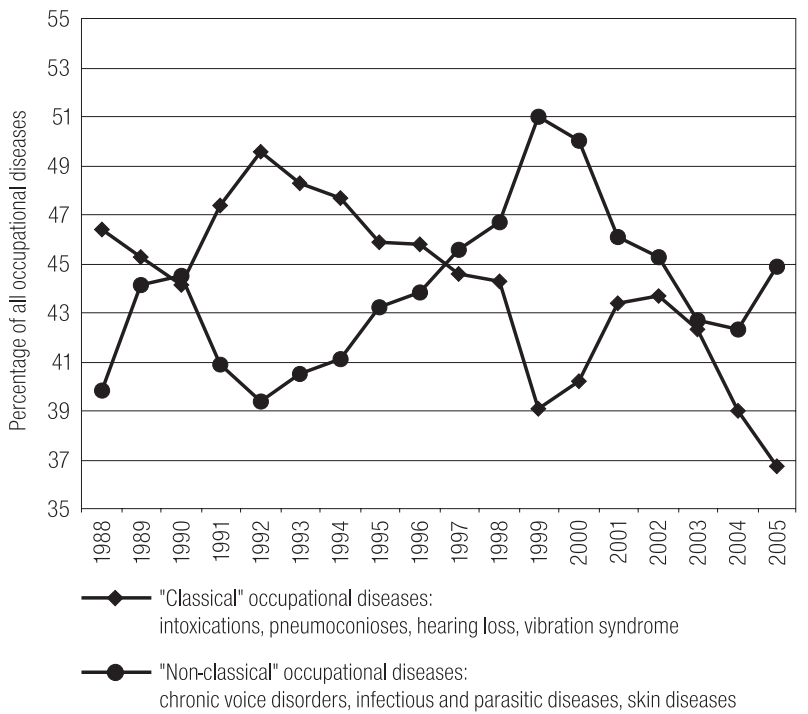

Fig. 7. Changes in the profile of diagnosed occupational diseases.

in 1999 the percentage of "non-classical" occupational diseases was higher than that of classical ones (about $51 \%$ vs. $39 \%)$.

\section{CONCLUSIONS}

The results of the analysis of occupational disease incidence in 2005 can be interpreted not only in terms of recent trends and tendencies. A large number of overlapping factors have contributed to the epidemiological situation regarding occupational diseases in Poland. The following categories of factors can be distinguished:

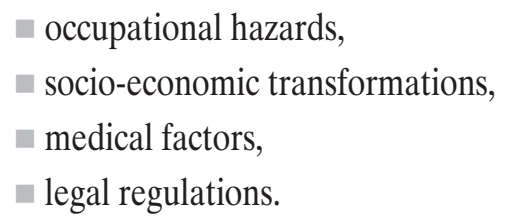

The main objective of occupational diseases monitoring is to identify the working conditions that induce their development, and to undertake effective preventive measures at hazardous workposts. The decreasing prevalence of some of occupational pathologies is most likely due to more effective surveillance of working conditions by work hygiene units of the State Sanitary Inspectorate. The type, magnitude and duration of exposure are the most essential factors determining the profile and prevalence of a given occupational disease. The changing characteristics of ex- 
posure over time brings about alterations in the level and structure of the incidence of occupational diseases.

The total number of registered cases and the incidence of occupational diseases have also been influenced by the general tendencies pertaining to the socio-economic transformations in Poland. The number of industrial workers has largely decreased as a result of closing down several dozen large industrial plants that used to employ several thousand workers. At the same time, the number of workers employed in small enterprises, trade and services and of self-employed workers has considerably increased. One can presume that in these occupational groups, the actual incidence of occupational diseases will be higher than that reported in official statistics. A similar hypothesis has been put forward by Morse et al. [7]. Identifying occupational hazards in small enterprises would provide grounds for making workplace prophylaxis operational [8].

The socio-economic conditions are directly related to the transformation processes and may contribute either to an increase or a decrease in the incidence of particular categories of occupational diseases. The unstable labor market and the high rate of unemployment may make the workers report their health complaints to have their case certified as an occupational disease, which enables them to receive compensation. On the other hand, some workers may conceal the experienced symptoms for fear of losing their job.

The actual number of cases reported to the Central Register also depends on a number of medical factors, including the diagnostic potential, large-scale prophylactic examinations, implementation of preventive measures, such as vaccination programs. Vaccinations against viral hepatitis B in the high risk group of health care workers, introduced in the mid 1990, may serve as a good example of highly effective preventive measure. In 2005, a sevenfold decrease in the number of cases of this pathology was noted compared with 1993 (151 vs. 1058).

However, medical examinations to protect workers against health effects of occupational exposure may also contribute to an unexpected increase in the number of diagnosed cases. A large number of cases of asbestosis recorded in 1982-1983 and 2001-2005 in asbestos plants covered by prophylactic examinations under the project co-ordinated by the Nofer Institute of Occupational Medicine reflects the impact of medical examinations.

The rate of certified cases of occupational diseases is also determined by legal regulations concerning their classification. This aspect makes the comparative studies particularly difficult and distorts the ranking of particular disease categories. For instance, in Poland voice disorders are the most prevalent occupational pathology while in the USA musculoskeletal conditions are at the top of the list. Likewise, the incidence ratio of occupational asthma in Poland (1.1 cases per 100000 workers in 2005) is several times lower than in Finland $[9,10]$. Frequently verified and amended regulations have their impact on the number of certified cases. Also the system of medical certification and compensation for occupational diseases has its own contribution [11].

Changes on the labor market, new technologies and most of all the tendency among workers to move to the service and administrative sectors, will certainly affect the profile of occupational and work-related pathologies. In the present-day work environment, the work-related stress (induced by the necessity to cope with new tasks, new work organization, or high pace of work) has become the dominating factor. The office work has also been associated with adverse health effects. Poland is not the only country where new health problems, resulting from dynamically changing conditions, should be incorporated into current registers of occupational diseases.

\section{REFERENCES}

1. Indulski JA, Starzyński Z. Occupational diseases in Poland in the years 1991-1993. Łódź: Nofer Institute of Occupational Medicine; 1994.

2. Directive of July 30, 2202 on the list of occupational diseases and detailed procedures of reporting on suspected, diagnosed, and certified occupational diseases and relevant institutions responsible for these matters, issued by the Council of Ministers. Off J Law 2002,132,115.

3. Wilczyńska U, Szeszenia-Dąbrowska N, Szymczak W. Occupational diseases in Poland, 2005. Med Pr 2006;57(3)225-234 [in Polish].

4. Pepłońska B, Szeszenia-Dąbrowska N. Occupational diseases in Poland, 2001. Int J Occup Med Environ Health 2002;15(4):337-45. 
5. Śliwińska-Kowalska M, Fiszer M, Kotyło P, Ziatkowska E, Stepowska M, Niebudek-Bogusz E. Effect of voice emission training on the improvement in voice organ function among students attending the college of teachers. Med Pr 2002;53(3):229-32 [in Polish].

6. Śliwińska-Kowalska M, Fiszer M, Niebudek-Bogusz E, Ziatkowska E, Kotyło P, Domańska M. The effectiveness of voice therapy for teachers with voice disorders. Med Pr 2003;54(4):319-25 [in Polish].

7. Morse T, Dillon C, Weber J, Warren N, Bruneau H, Fu R. Prevalence and reporting of occupational illness by company size: population trends and regulatory implications. Am J Ind Med 2004;45(4):361-70.

8. Okun A, Lentz TJ, Schulte P, Stayner L. Identifying high-risk in small business industries for occupational safety and health interventions. Am J Ind Med 2001;9(3):301-11.
9. Courtney TK, Webster BS. Antecedent factors and disabling occupational morbidity - insights from the new BLS data. AIHAJ 2001;62(5):622-32.

10. Karjalainen A, Kurppa K, Virtanen S, Keskinen H, Nordman H. Incidence of occupational asthma by occupation and industry in Finland. Am J Ind Med 2003;37(5):451-8.

11. Azaroff LS, Levenstein C, Wegman DH. Occupational injury and illness surveillance: conceptual filters explain underreporting. Am J Public Health 2002;92(9):421-9. 